\title{
Using Surgicel $\circledast$ Plug to Prevent Trocar Site Hernia after Laparo- scopic Surgery in Obese Patients
}

\author{
Fady Makram, MD, FACS \\ Department of General Surgery, Ain Shams University, Cairo, Egypt
}

Background: Incisional hernia and wound dehiscence are common complications after abdominal surrgery. The development of minimally invasive surgical techniques has led to a dramatic decrease in these complications. Ten-millimeter and wider ports are often used in laparoscopic surgery. It could be difficult to close the ports sites, especially in obese patients, so, laparoscopic surgery may still be followed by trocar site herniation. Various methods have been advocated for its prevention. The aim of this study was to try a new method to prevent trocar site hernia in obese patients.

Patients and methods: This prospective interventional non-randomized non-controlled study was conducted in the Department of General Surgery at Ain Shams University hospitals in the period from November 2013 to November 2016 on 150 obese (Body mass index (BMI) $>35 \mathrm{~kg} / \mathrm{m}^{2}$ ) patients ( 50 males and 100 females) who underwent laparoscopic surgery (70 cholecystectomies, 25 gastric bypass surgeries, 35 sleeve gastrectomies and 20 appendectomies). In all patients, the fascial layer of trocar wounds was not closed. Instead, a Surgicel $\circledast$ plug was inserted into the muscle layer of trocar wounds. Informed consent was obtained from all patients included in the study.

Results: One case, out of the included 150 obese patients, after laparoscopic gastric bypass developed port site hernia with an incidence of $0.67 \%(1 / 150)$. In both patients, hernia was uncomplicated. No patient in the other groups has been found to develop a hernia.

Conclusion: Surgicel ${ }^{\circledR}$ plug is an easy technique with very low incidence of trocar site hernia after laparoscopic procedures in obese patients.

Key words: Trocar site herniation, laparoscopic surgery, Surgicel $\Re$.

\begin{abstract}
Introduction
Trocar site hernia was defined as the development of a hernia at the cannula insertion site. ${ }^{1}$ Herniation through port site wounds is the result of inadequate closure of the musculoaponeurotic layer of the abdominal wall. The overall percentage is size related with the majority of hernias occurring in wounds larger than $10 \mathrm{~mm}$ ports. ${ }^{2}$
\end{abstract}

Port site hernia is an important yet underrecognized complication of laparoscopic surgery, which carries a high risk of strangulation due to the small size of the defect involved. ${ }^{3}$ The incidence of trocar hernias ranges from $0.2 \%$ to $3.1 \% .{ }^{4}$ There are numerous ways of closing laparoscopic wound. However, it is difficult in obese patients. ${ }^{5}$ Secure fascial closure has been reported to decrease this complication. However, it is often difficult to directly visualize the fascia through these tiny incisions during the standard hand-sutured closure. ${ }^{6}$ In morbidly obese patients, a thick preperitoneum predisposes to the development of the Richter hernia, despite adequate fascial closure. ${ }^{7}$

The aim of this study was to detect the possibility of using a Surgicel $\AA$ plug without fascial closure to prevent trocar site hernia.

\section{Patients and mtethods}

This prospective interventional non-randomized non-controlled study was conducted in the Department of General Surgery at Ain Shams University hospitals in the period from November 2013 to November 2016 on 150 obese (BMI>35 $\mathrm{kg} / \mathrm{m}^{2}$ ) patients (50 males and 100 females) who underwent laparoscopic surgery. This included patients with wide fascial wounds after difficult extraction of gall bladder in laparoscopic cholecystectomy $(n=70)$, patients after laparoscopic gastric bypass surgery $(n=25)$, patients after laparoscopic sleeve gastrectomy $(n=35)$ and patients after laparoscopic appendectomies $(n=20)$. Informed consent was obtained from all patients included in the study.

Patients unfit for laparoscopic surgery or who required conversion to an open approach, patients with port wound complications as hematoma or infection and those who failed to attend for postoperative follow-up were excluded from the study.

Forall patients, medical and surgical historyaswell as routine preoperative investigations were done according to the indicated surgery. Standard 
follow-up for all patients was within two weeks from hospital discharge. Subsequent follow up was at three months intervals.

During the operations, all patients received general anesthesia, endotracheal intubation and were put in the standard position according to the type of surgery.

\section{Technique of trocar insertion and wound closure:}

First, pneumoperitoneum was established via a Veress needle with intraabdominal pressure up to $15 \mathrm{mmHg}$. The technique of laparoscopic cholecystectomy was through 4 ports in the standard positions while the technique of laparoscopic appendectomy was through 3 ports and that of laparoscopic gastric bypass and laparoscopic sleeve gastrectomy were through 5-6 ports.

The initial trocar was advanced with a steady pressure and feeling the spread through fascia, muscle, peritoneum and then into the peritoneal cavity (transperitoneal technique). Other ports were placed under vision on the video monitor with the same technique. Different brands of disposable trocars (non-bladed and bladed) were used randomly.

At the end of surgery, the ports were removed under direct vision from the camera port to make sure there was no bleeding or any visceral entrapment.

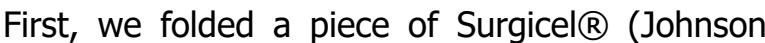
\& Johnson) as a plug and inserted it into the abdominal cavity via the port. Then, we withdrew the port through the muscle layer slowly retracting the Surgicel ${ }^{\circ}$ plug out and left it inside the muscle layer. Finally, the port was removed (Figure 1). All trocar wounds $\geq 10$ $\mathrm{mm}$ were managed with the same procedure. The subcutaneous layer was closed with interrupted 2-0 Vicryl sutures, and the skin was closed with interrupted 3-0 Monocryl sutures. No fascial closure of these port sites was done.

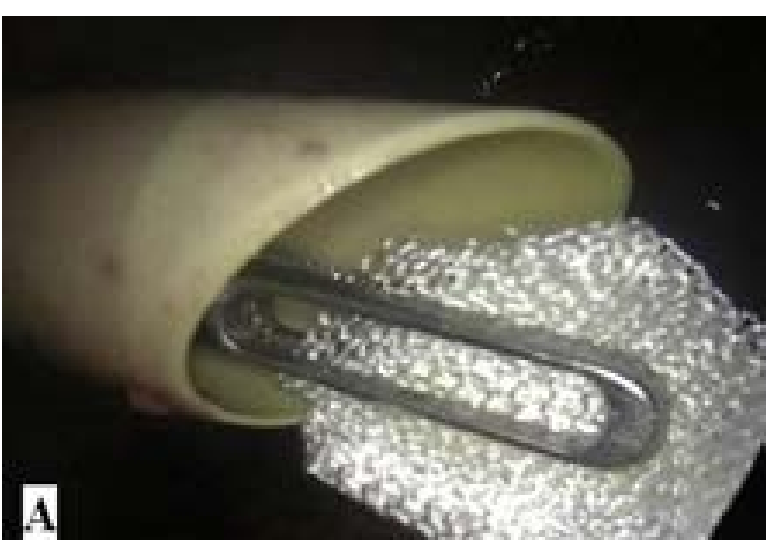

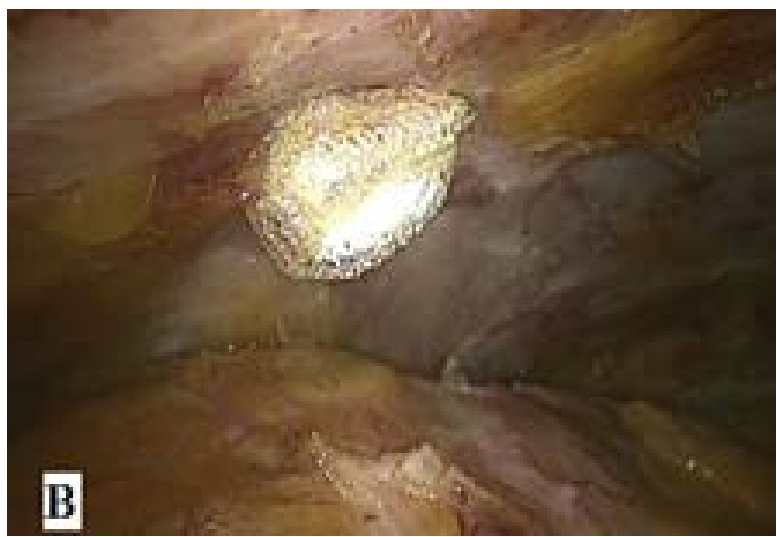

Fig 1A: Introduction of the Surgicel $\circledast$ plug, B: Final position of the Surgicel®plug.

Desufflation of the peritoneal cavity was completed via the camera port before it was removed, thus, it was expected that the bowel or omentum would not be sucked into the wound with the $\mathrm{CO}_{2}$ just following port removal.

\section{Statistical methodology:}

Data were coded and entered using the statistical package SPSS (Statistical Package for the Social Science) version 23. Data was summarized using mean, minimum and maximum in quantitative data and using frequency (count) and relative frequency (percentage) for categorical data.

\section{Results}

Patients' demographics: (Table 1)

Our study consisted of 150 obese patients: 50 males (33.33\%) and 100 females (66.66\%).

The mean age was 33.5 years (range 19-57 years). The preoperative mean body weight was $92 \pm 22.5 \mathrm{~kg}$ (range $80.5-220.7 \mathrm{~kg}$ ), and the body mass index (BMI) was $42.3 \pm 8.6 \mathrm{~kg} / \mathrm{m} 2$ (range $\left.37.5-68.0 \mathrm{~kg} / \mathrm{m}^{2}\right)$.

Table 1: Patients' demographics

\begin{tabular}{llll}
\hline & & Number & Percentage \\
\hline \multirow{2}{*}{ Sex } & Male & 50 & $33.33 \%$ \\
& Female & 100 & $66.66 \%$ \\
Age (Years) & Mean \pm SD & Minimum & Maximum \\
& 33.5 & 19.00 & 57.00 \\
Body weight & Mean \pm SD & Minimum & Maximum \\
(Kg) & $92 \pm 22.5$ & 80.50 & 220.70 \\
BMI $(\mathrm{Kg} / \mathrm{m} 2)$ & Mean \pm SD & Minimum & 68.00 \\
Mean $\pm S D$ & $42.3 \pm 8.6$ & 37.50 & 68.00 \\
\hline
\end{tabular}

At a mean follow-up time of 25 months (range 12 to 36 months) for these 150 patients, trocar site hernia was detected in one female patient after laparoscopic gastric bypass with an overall incidence of $0.67 \%(1 / 150)$. The patient was 47 years old. She was asymptomatic and she 
had no history of previous abdominal surgery and was not diabetic. Body mass index was $45.6 \mathrm{~kg} / \mathrm{m}^{2}$. She had neither wound infection nor wound hematoma after the operation. The interval between surgery and diagnosis was 10 months. Trocar site hernia occurred at the 12- $\mathrm{mm}$ trocar wound in the right midclavicular line, $5 \mathrm{~cm}$ below the costal margin. A protruded soft mass was noted at this trocar wound during abdominal muscle exertion. She did not develop intestinal obstruction or peritonitis (Table 2).

Table 2: The case developed port site hernia

\begin{tabular}{|c|c|c|c|c|}
\hline Number of cases & Original surgery & Main complaint & Time of diagnosis & Trocar size \\
\hline $0 / 70$ & Laparoscopic cholecystectomy & ---------- & ---------- & ---------- \\
\hline $1 / 25$ & Laparoscopic gastric bypass & Asymptomatic & 10 months & $12 \mathrm{~mm}$ \\
\hline $0 / 35$ & Laparoscopic sleeve gastrectomy & ---------- & ---------- & ---------- \\
\hline $0 / 20$ & Laparoscopic appendectomy & ----------- & ---------- & ---------- \\
\hline
\end{tabular}

\section{Discussion}

Tonouchi et al., $2004^{8}$ recognized the first report in the literature of a port site hernia in the context of gynecological surgery (1968). The first publication of a port site hernia following laparoscopic cholecystectomy was in 1991 by Maio et al, ${ }^{9}$ whilst this complication has long since been recognized, its significance is becoming more important with the increasing number of patients being treated in that way. In addition to pain, port site hernia can lead to severe complications, including bowel obstruction, strangulation, and perforation. ${ }^{10}$

The reported incidence of this specific complication ranges from $0.2 \%$ to $3.1 \%$, with an average of $1 \%$ in most series published ${ }^{4}$ which is higher than the incidence in our study using a Surgicel ${ }^{\circledR}$ plug. However, the true incidence may be underestimated for a variety of reasons, such as failure to diagnose, delay in diagnosis, patient tolerance of asymptomatic hernia and inability to follow up. ${ }^{11}$

Obese patients are at a high risk for preperitoneal hernias because of their elevated intra-abdominal pressure and substantially thicker fatty preperitoneum. Besides, this thick fatty preperitoneum is potentially a space for intestinal incarceration, with the peritoneum acting as the strangulating ring, despite adequate fascial closure. Also, it is not easy to securely close the fascial defect in obese patients. ${ }^{12}$

Risk factors related to trocar wound herniation may be divided into clinical and technical (mechanical) aspects. Clinical factors include male sex, advanced age, poor nutrition, anemia, diabetes mellitus, renal failure, treatment with steroids, advanced malignancy, and obesity. Technical and mechanical factors include sharp-bladed trocar-tip, larger trocar size, open laparoscopy (Hasson trocar insertion), stretching the port-site during manipulation, the technique of closure, properties of the suture materials used for closure, and location of the incision. ${ }^{13}$
Montz et al., $1999^{14}$ found that of 840 hernias in which the trocar size was known, $86 \%$ occurred in connection with trocars $>10 \mathrm{~mm}$. Kadar et al., $1993^{15}$ reported an incidence of $0.23 \%$ ( 1 in 429 patients) by the application of $10-\mathrm{mm}$ trocars, rising to $3.1 \%$ (5 in 161 patients) when $12-\mathrm{mm}$ trocars were used.

It is generally recommended that fascia of $5-\mathrm{mm}$ trocar incisions not be closed, while that of 10 to $12 \mathrm{~mm}$ trocar incisions to be closed at the end of laparoscopic procedures because of the increased risk of trocar wound hernias. ${ }^{16}$

Tarnay et al., $1999^{13}$ found that the blunt conical trocars created smaller fascial defects than both the pyramidal and the cutting dilating trocars with reduced risk of trocar site herniation. These conclusions were supported by data from Lajer et al., $1997^{17}$ who found a reduction of trocar site herniations from $2 \%$ to $0.2 \%$ when a conicalshaped trocar was used in place of a sharp cutting trocar.

Montz et al., $1999^{14}$ showed, in a survey of 933 trocar site hernias, that $17.9 \%$ still occurred although fascial closure had been performed. Gallery et al., $1996^{18}$ stated that all large trocar sites should be closed meticulously, even if the skin incision had to be extended. Some authors even suggested that larger trocar sites be closed completely with adequate muscle relaxation. Elashry et al., $1996^{19}$ recommended that closure be done with a fascial closure device (Carter-

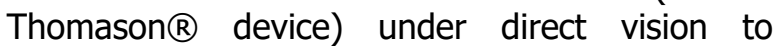
ascertain adequate closure of the fascial defect. Rid and Collins, $2005^{16}$ also found that the CarterThomason closure System $\mathrm{XL}^{\mathrm{TM}}$ (Inlet Medical, Eden Prairie, MN, USA) resulted in a superior closure (Figure 2), however, some surgeons believe that use of such devices is timeconsuming and costly, while others advocates $Z$ trocar insertion for all abdominal trocar perforations to avoid later hernias. ${ }^{20}$ 


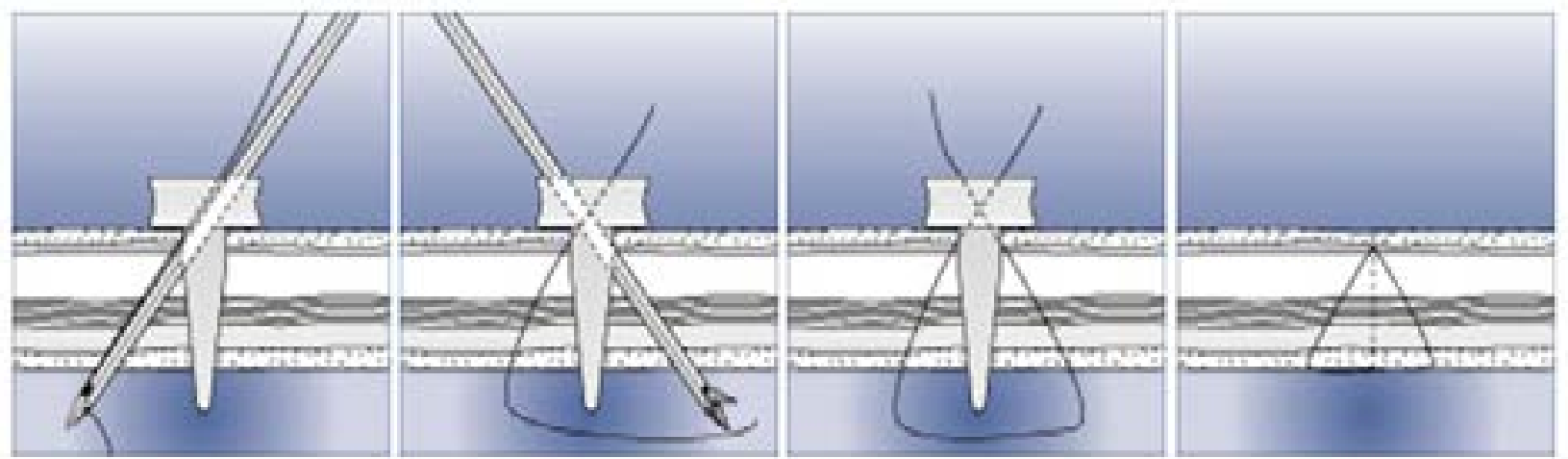

Fig 2: Carter-Thomason closure system.

The presenting technique performs no fascial closure of all trocar site wounds after port removal. Instead, we fold a small piece of Surgicel ${ }^{\circledR}$ as a plug and insert it into the muscle layer of trocar wounds of $10 \mathrm{~mm}$ and $12 \mathrm{~mm}$ size.

Surgicel $\AA$, an oxidized regenerated cellulose hemostat, has proven to be a safe and reliable product that offers some advantages over other topical hemostatic agents including ease of use, efficacy on many types of bleeding surfaces, antibacterial action, biocompatibility, and trivial mass effect. It did not incite an inflammatory or foreign body reaction, and it retarded the formation of adhesions with the intestine. ${ }^{21} \mathrm{~A}$ study revealed that the average time of trocar wound herniation was within 10 days after operation.

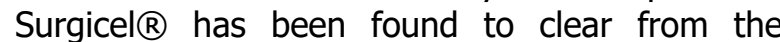
implantation site in 1 week, which is likely adequate for separated muscle fiber healing and approximation. ${ }^{21}$

The initial result of trocar site herniation was $0.67 \%(1 / 150)$. The short-term results appears favorable. However, a randomized prospective comparison with other techniques is required to determine long-term benefits.

\section{Conclusion}

Laparoscopic surgery offers obese patients greater comfort in the postoperative period, short hospital stay and quick return to physical activities, however, postoperative hernia may still be an infrequent complication. This method of Surgicel $\mathbb{R}$ plug insertion is an easy technique with very low incidence of trocar site hernia after laparoscopic procedures in obese patients. It may have some advantages and can be applied safely in patients with high risk for trocar site hernia.

\section{References}

1. Crist DW, Gadacz TR: Complications of laparoscopic surgery. Surg Clin North Am
1993; 73: 265-289.

2. Cuscherie A, Houston G: Essential of surgical practice. 4th ed. Abdominal Minimal Access Surgery 2000; 1: 508.

3. Owens $M$, Barry $M$, Janjua $A Z$, Winter $D C$ : $A$ Systematic review of laparoscopic port site hernia in gastrointestinal surgery. Surgeon 2011; 9: 218-224.

4. Yamamoto M, Minikel L, Zaritsky E: Laparoscopic 5-mm trocar site herniation and literature review. JSLS 2011; 15: 122-126.

5. Durai R, Ng PC: Novel methods of closing 10$\mathrm{mm}$ laparoscopic port-site wounds. Journal of Laparoendoscopic \& Advanced Surgical Techniques 2009; 19: 791-793.

6. Di Lorenzo N, Coscarella G, Lirosi F, Gaspari A: Port-Site Closure: A new problem, an old device. JSLS 2002; 6: 181-183.

7. Johnson $\mathrm{WH}$, Fecher $\mathrm{AM}$, McMahon RL, Grant JP, Pryor AD: VersaStep trocar hernia rate in unclosed fascial defects in bariatric patients. Surg Endosc 2006; 20: 1584-1586.

8. Tonouchi $\mathrm{H}$, Ohmori $\mathrm{Y}$, Kobayashi M, Kusonoki M: Trocar site hernia. Arch Surg 2004; 139: 1248-1256.

9. Maio A, Ruchman RB: CT diagnosis of postlaparoscopic hernia. J Comput Assist Tomogr 1992; 15: 1054-1055.

10. Dulskas A, Lunevičius R, Stanaitis J: A case report of incisional hernia through a 5 $\mathrm{mm}$ lateral port site following laparoscopic cholecystectomy. Journal of Minimal Access Surgery 2001; 7: 187-189. 
11. Hussain A, Mahmood H, Singhal T, Balakrishnan S, Nicholls J, El-Hasani S: Long-term study of port-site incisional hernia after laparoscopic procedures. JSLS 2009; 13: 346-349.

12. Cottam DR, Gorecki PJ, Curvelo M, Weltman D, Angus LD, Shaftan G: Preperitoneal herniation into a laparoscopic port site without a fascial defect. Obes Surg 2002; 12: 121-123.

13. Tarnay CM, Glass KB, Munro MG: Incision characteristics associated with six laparoscopic trocar-cannula systems: A randomized, observer-blinded comparison. Obstet Gynecol 1999; 94: 89-93.

14. Montz FJ, Holschneider $\mathrm{CH}$, Munro MG: Incisional hernia following laparoscopy: A survey of the American Association of Gynecologic Laparo-scopists. Obstet Gynecol 1994; 84: 881-884.

15. Kadar N, Reich H, Liu CY, Manko GF, Gimpelson R: Incisional hernias after major laparoscopic gynecologic procedures. Am J Obstet Gynecol 1993; 8: 171-178.

16. Eid GM, Collins J: Application of a trocar wound closure system designed for laparoscopic procedures in morbidly obese patients. Obes Surg 2005; 15: 871-873.

17. Lajer $\mathrm{H}$, Widecrantz $\mathrm{S}$, Heisterberg L: Hernias in trocar ports following abdominal laparoscopy: A review. Acta Obstet Gynecol Scand 1997; 76: 389-393.

18. Gallery MP, Strasberg SM, Soper NL: Complications of laparoscopic general surgery. Gastrointest Endose Clin N Am 1996; 6: 423444.

19. Elashry OM, Nakada SY, Wolf JS, Figenshau, McDougall, Clayman: Comparative clinical study of port-closure techniques following laparoscopic surgery. J Am Coll Surg 1996; 183: 335-344.

20. Shalhav AL, Barret $E$, Lifshitz DA, Stevens $L H$, Gardner TA, Lingeman JE: Transperitoneal laparoscopic renal surgery using blunt $12 \mathrm{~mm}$ trocar without fascial closure. J Endourol 2002; 16: 43-46.

21. Arnar AP, Levy ML: Applications of topical hemostatic agents in neurosurgery. Contemp Surg for Residents 1996; 4: 19-22. 